\title{
BACTERIOLOGICAL CONTROL IN A BLOOD BANK: A REPORT
}

\author{
André Potvin, M.D., ${ }^{1}$ and FeRnando Hudon, M.D., F.R.C.P. (c) ${ }^{2}$
}

AMONG THE AUTHORs who have studied bacterial contaminants of blood, Braude (1) reports contamination by gram $_{\top}$ positive and gram-negative microbes. The former comprise pathogenic staphylococci and diphtheroids which do not cause serious reactions in man. The latter are much more dangerous and are known to be responsible for severe shocks on account of their endotoxins $(2,3,4)$. As stated by Braude, Corey, and Siemienski (5) these gram-negative germs can be divided into two groups according to their physiology:

1. A first group comprises saprophytic species belonging to the genera Pseudomonas and Achromobacter. These bacilli are cryophillic: their optimum temperature being between $4^{\circ}$. and $8^{\circ}$. C.; when incubated at $37^{\circ} \mathrm{C}$.; the growth is very poor and slow to develop.

2. A second group contains microbes of the coli-aerogenes group: E. coli, E. freundii, E. intermedium. Pittman (6) reports other gram-positive contaminants such as:" streptococci, sarcina, and B. cereus. He also cites bloéd contamination by Paracolon intermedium, Paracolon aerogenoides, Faecalis alcaligenes, and other germs capable of utilizing citrate as the sole source of carbon. In eighteen fatal transfusions, he has found eight strains of the genus Pseudomonas. However, Pseudomonas aeruginosa was not involved in these accidents.

According to Braude (1), the rate of contamination in blood banks is between 2 and 3 per cent. Reactions are rare and occur only when blood is heavily contaminated. In England, during the war, 1939 to 1945, blood contamination in blood banks was about 5 per cent according to Whilly (7), while in New York, during the same period, Heath and Angrem (8) reported an 8.5 per cent contamination calculated on a quantity of $6,151 \mathrm{~L}$. blood. Walter, Kundsin, and Button (9) report 47 contaminations from 4,497 specimens (1.04 per cent) in which were found Staph. aureus, streptococci, a flavobacterium, yeasts, aspergilli, and penicillium.

The reason why slight contamination is not very dangerous is that fresh blood has antibacterial properties apparently related to the presence of antibodies and complement as pointed out by Geller, Chandler and Janetz (10), also of properdin according to Wardlay and Pillemer (11). These properties seem to be enhanced by gran-negative microbes following a short period of incubation at $37^{\circ} \mathrm{C}$., before the storage of the blood in the bank; this activity is not so evident for cryophillic bacteria which later multiply in the refrigerator. Low temperatures are believed to inhibit these antibacterial factors. This present paper deals with the search for bacterial contaminants in a normally operated blood bank. Its aim was to control the sterility of the blood and to compare methods and results with the data from the above-mentionned authors.

1 Bacteriologist, Hôtel-Dieu Hospital, Quebec, P.Q.

${ }^{2}$ Chief Anesthetist, Hôtel-Dieu Hospital, Quebec, P.Q. 


\section{Matzinial and Techintoue}

The samples were taken from the blood bank of the Hôtel-Dieu Hospital in Quebec City during October 1958, the blood having been kept in the refrigerator at $6^{\circ}$ to $8^{\circ} \mathrm{C}$. for periods varying from two to 31 days. By preference, the loldest specimens were chosen so that even the slowest growing organisms such as spores, fungi, or cryophillic bacteria might be detected. Blood specimens were taken from the containers (rubber caps well cleaned with $70^{\circ}$ alcohol) in a most aseptic manner by the anaesthetist and the bacteriologist assisted by a nurse, all three wearing masks. $2.5 \mathrm{ml}$. were withdrawn and inoculated immediately. into a test tube containing $7.5 \mathrm{ml}$. thioglycollate liquid medium. ${ }^{3}$ (Thioglycollate medium has long been recommended for sterility tests; it may be used alone, with methylene blue or even better still with resazurin as an $\mathrm{rh}$ indicator, Pittman (12)). The last drop of the blood in the syringe was used for a direct examination. In this way, 58 specimens were collected; of these, 30 were taken from glass containers, ${ }^{4}$ the remaining from plastic bags. ${ }^{5}$ All specimens were incubated for one month: 15 days at $37^{\circ} \mathrm{C}$, and 15 days at room temperature $\left(20^{\circ}\right)$.

Following this incubation period, a second direct examination was made for all tubes and a gram staining was done whenever necessary. May we stress the necessity of making direct examination, because apparently one cannot rely on the clarity of the culture media to conclude that they are sterile; as a matter of fact, Wichelhausen, Clark, Griffing, and Robinson (13) have shown that a solution of human serum-albumin diluted to 25 per cent may be quite contaminated without showing any turbidity. These authors have thus isolated from

TABLE 1

\begin{tabular}{ccc}
\hline Number of cases & $\begin{array}{c}\text { Storage times (days) at } \\
6 \text { to } 8^{\circ} \mathrm{C} .\end{array}$ & $\begin{array}{c}\text { Results obtained after } 15 \text { days } \\
\text { at } 37^{\circ} \mathrm{C} \text {. and } 15 \text { days at } 20^{\circ} \mathrm{C} .\end{array}$ \\
\hline 1 & 31 & \\
3 & 30 & \\
2 & 23 & Both direct examinations and \\
1 & 21 & \\
4 & 20 & \\
1 & 19 & \\
3 & 17 & \\
3 & 16 & \\
3 & 15 & \\
2 & 13 & \\
3 & 10 & Thltures were negative. \\
5 & 9 & of Faecalis alcaligenes. \\
12 & 8 & Both direct examinations and \\
2 & 7 & cultures were negative. \\
3 & 6 & \\
\hline 4 & 5 & \\
\hline 5 & 2 &
\end{tabular}

8No 01-140, Baltimore Biological Laboratoty Inc.

4Transfuso-vac., F. 83, Baxter Laboratories of Cenada, Acton, Ont.

sPliapak A.D.C. Solution, Abbott Laboratories, Montreal, 
clear sera the following organisms: $C$. albicans, Proteus vulgaris, P.aeruginosa, and Streptococcus faecalis.

Table I summarizes the procedures follpwed and also the results.

\section{ResULTS AND Discusston}

Only three specimens of blood from glass containers gave positive cultures (Faecalis alcaligenes) after 25 days of incubation. It is most probable that these specimens were contaminated in the laboratory, as: (i) the cultures were examined macroscopically every day, and turbidity appeared only on the twentyfifth day, after 15 days of incubation at $37^{\circ} \mathrm{C}$., and 10 days at $20^{\circ} \mathrm{C}$.; (ii) the plasma haemoglobin content of the three specimens of blood was very low; (iii) the patients who received the blood presented no reaction whatever.

These contaminations have undoubtedly occurred through the cotten plugs of the culture tubes. In order to prevent such casualties, it may be advisable to seal the tubes or to use rubber caps. According to Marfarlane, Mainwaring, Maesween, and Parish (14), it is most difficult to avo1d contamination when cultures have been inoculated for a long period of time, a the described a method for sealing the tubes.

As noted previously, only massive contaminations cause serious post-transfusion accidents. It may be of interest to recall briefly that reactions occur thirty minutes or more after the transfusions. The symptoms are chills, temperature, muscular algia, hypotension, and shock which naay be fatal (15-17). As stated by Braude (1), such accidents can be prevented by taking the following precautions: (i) a direct examination of the blood immediately before the transfusion; (ii) a routine use of $20 \mathrm{mg}$. of tetracycline per litre of blood. Braude recommends these precautions when storage conditions are poor, or when difficult manipulations are inevitable as in wartime or during a civil catastrophe.

In order to prevent an eventual multiplication of microbes, the time lapse between the collection of the blood and the transfusion should be as short as possible. According to Braude (1), the bacterial multiplication may reach important proportions in a week or two, in such a manner. as to give concentrations of $10^{9}$ to $10^{11}$ germs per millilitre.

We believe that whenever procedures of collecting blood have been long and difficult, the laboratory should proceed to immediate cultures and that such blood should be used within a week. A direct examination and a gram staining made immediately before the transfusion are advised. Stevens, Legg, Henry, Dille, Kerby, and Finch (4);recommend a staining just before transfusion. According to Walter et al. (9), a sterility test should be made before a transfusion, whenever the blood has been refrigerated for more than 96 hours. These same authors also describe a new technique for the detection of blood contaminants by the use of plastic equipment which seems to lessen the risks of contamination, in comparison to glass containers.

IONCLUSION

After 25 days of incubation three blood bank specimens out of 58 were con- 
taminated with Faecalis alcaligenes. These contaminations occurred in the laboratory, as the other 55 samples remained sterile even after one month of incubation. This was made evident by a gram stain of the cultures.

In a well-organized blood bank, contamination can be avoided, at least in blood specimens used for transfusions, by having this service conducted under the supervision of an anesthetist working in close co-operation with the laboratory staff.

\section{SUMMaRY}

Fifty-eight specimens of blood from a blood bank were inoculated in fluid thioglycollate, and incubated 15 days at $37^{\circ} \mathrm{C}$., and 15 days a't $20^{\circ} \mathrm{C}$., for sterility control; only three yielded a culture of Faecalis alcaligenes on the twenty-fifth day of the experiment, and it is assumed that this was caused by a contamination in the laboratory.

A general review of the subject is given, along with a discussion of the prophylaxis of blood bank contamination.

\section{RÉSUMÉ}

Cinquante-huit spẹcimens venant d'une banque de sang ont été ensemencés dans du thioglycollate liquide et incubés durant 15 jours à $37^{\circ} \mathrm{C}$., et durant 15 autres jours a $20^{\circ} \mathrm{C}$; pour contrôle bactériologique. Trois échantillons ont donné une culture de Faecalis alcaligenes au vingtième jour de l'expérience; selon toute évidence, il s'agissait d'une contamination survenue au laboratoire.

Une revue générale de la question est éxposée, ainsi que les moyens à prendre pour prévenir la contamination du sang des banques.

\section{REFERENCES}

1. Braude. A. 'D. Transfusion Reactions from Contaminated Blood. Ncw Eng. J. Med. 258्:1289 (1958).

2. Briude, A. J.; Willams, D.; Siemiensku, J.; \& Murphy, R. Shock-like State due to Trahsfusion of Blood Contaminated with Gram-negative Bacilli: Successful Treatment with Antibiotics and Arterenol. Arch. Int. Med. 39:1228 (1953):

3. Borden, C. W., \& HALI, W. H. Fatal Transfusion Reactions from Massive Bacterial Contamination of Blood. New Eng. J. Med. 245:760 (1951):

4. Stevens, A. R.; Legc, J. S.; Henay, B. S.; Dille, J. M.; Kkrby, W. N. M.; \& Fanch, C. A. Fatal Transfusion Reactions from Contamination of Stored Blood by Cold Growing Bacteria. Ann. Int. Med. 39:1225 (1953).

5. Braude, A. J., Cokey, P. J., \& Sirmensm, J. Studies of Bacterial Transfusion Reactions from Refrigerated Blood: Properties of Cold Growing Bacteria. J. Clin. Invest. 39:311 (1955).

6. Prtrman, M. Study of Bacteria Implicated in Transfusion Reactions and of Bacteris Isolated from Blood Products. J. Lab. \& Clin. Med. 42:273 (1953).

7. WhrLdy, L. Blood Transfusion, ed. G. Keynes. Bristal: John Wright \& Sons Ltd. (1940).

8. Heath, F. K., \& AMgren, J. Preservation of Human Plasma: Report of Studies with Sulfonamide Compounds. J.A.M.A. 118:1034 (1942).

9. Walten, C. W., KúnDsn, R. B., \& Butron, L. N. New Technic for Detection of Bacterial -Contamination in a Blood Bank using Plastic Equipment. New Eng. J. Med. 257 (7): RR4 3R9 (19.57). 
10. Geller, P., Chandler, A. B., \& JaNetz,-E. Experimental Studies on Bacterial Contaminations of Bank Blood. J. Lab. \& Clin. M. 49(4):573 (1957),

11. Wafdlaw, A., \& Prluemer L. The Properdin System and Imunity. J. Exper. Med. 103:553 (1956).

12. Pitrman, M. A Study of Fluid Thioglyeollate Medium for the Sterility Test. J. Bact. 51:19-30 (1946).

13. Wichelinausen, R. H.; Clark, H. W.; Griffing, V. F.; \& Robinson, L. B. The Concealment of Heavy Bacterial Contamination in 25 per cent Human Serum Albumin: Its Mechanism and Clinical Significance. J. Lab. \& Clin. Med. 51:277 (1958).

14. Macfirlane, R. C.; Manwharing, J. C.; Maeswien, J. C.; \& Parush, H. J. Technique for the Filtration of Human Plasma and Serum for Transfusion. Brit. Med J. 1:377 (1942).

15. Braude, A. J.; Siemiensin, J.; Whriams, D.; \& SAktorord, J. P. Overwhelming Bacteriemic Shock Produced by Gram-positive Bacilli: Report of Four Cases with One Recovery. Univ. Michigan M. Bull. 19:23 (1953).

16. WeI, M. H., \& SpINR, W. W. Shock Syndrome Associated with Bacteremia due to Gram-negative Bacilli. Arch. Int. Med. 101:184 (1958).

17. Hall, H. W., \& Gold, D. Shock Associated with Bacteremia: Review of Thirty-five Cases. Arch. Int. Med. 96:403 (1955). 